\title{
A clinical and genetic study of 33 new cases with early-onset absence epilepsy
}

\author{
Lucio Giordano $^{\mathrm{a}, *}$, Aglaia Vignoli ${ }^{\mathrm{b}}$, Patrizia Accorsi ${ }^{\mathrm{a}}$, Jessica Galli ${ }^{\mathrm{b}}$, \\ Marianna Pezzellac , Monica Traverso ${ }^{c}$, Silvia Battaglia ${ }^{a}$,
} Maria Giuseppina Baglietto ${ }^{d}$, Francesca Beccaria ${ }^{e}$, Caterina Cerminara ${ }^{f}$, Silvia Gambara ${ }^{a}$, Ennio Del Giudice ${ }^{g}$, Giovanni Crichiutti ${ }^{\text {h }}$, Francesca Bisulli ${ }^{i}$, Mariangela Pinci ${ }^{f}$, Paolo Tinuper ${ }^{i}$, Eleonora Briatore ${ }^{j}$, Stefano Calzolari ${ }^{j}$, Antonietta Coppolak ${ }^{k}$, Maria Paola Canevini ${ }^{b}$, Giuseppe Capovilla ${ }^{e}$, Salvatore Strianok, Federico Zara ${ }^{c}$, Carlo Minetti ${ }^{c}$, Pasquale Striano ${ }^{c, *}$

a UO Neuropsichiatria Infantile, Centro Regionale Epilessia, Spedali Civili, Brescia, Italy

${ }^{\mathrm{b}}$ Epilepsy Center, San Paolo Hospital, University of Milan, Milan, Italy

' Muscular and Neurodegenerative Disease Unit, Laboratory of Neurogenetics, Istituto 'G. Gaslini', Università di Genova, Genova, Italy

'Child Neuropsychiatry, 'G. Gaslini Institute', University of Genova, Genova, Italy

e Child Neuropsychiatry, "C. Poma" Hospital, Mantova, Italy

${ }^{f}$ Child Neurology and Psychiatry, University of Tor Vergata, Roma, Italy

g Child Neurology Unit, Department of Pediatrics, Federico II University, Napoli, Italy

h Department of Pediatrics, University of Udine, Udine, Italy

' Department of Neurological Sciences, University of Bologna, Bologna, Italy

${ }^{j}$ Neuropsichiatria Infantile, S. Croce e Carle, Cuneo, Italy

${ }^{k}$ Epilepsy Center, Federico II University, Napoli, Italy

Received 13 January 2011; received in revised form 15 March 2011; accepted 25 March 2011

Available online 4 May 2011

\section{KEYWORDS}

Absence epilepsy;

Early-onset;

IGE;

SLC2A1;

EEG;

Therapy

\section{Summary}

Purpose: To investigate the electroclinical features and the outcome of patients with typical absences starting before the 3 years of life.

Methods: We reviewed the clinical data of patients with absences started before 3 years observed over a 15-year period. Mutation analysis of SLC2A1 (GLUT-1) gene was performed when possible. Their clinical features were compared with those of subjects with a diagnosis of childhood absence epilepsy (CAE).

\footnotetext{
* Corresponding authors.

E-mail addresses: pafivan@libero.it (L. Giordano), pstriano@email.it (P. Striano).
} 
Results: Among 33 children with absence epilepsy starting before 3 years of life, there were 20 boys and 13 girls. Mean seizure onset was at $28.0 \pm 8.3$ (range: $8-36$ ) months of life. Two children displayed borderline intellectual functioning at long-term follow-up. Twenty-eight (85\%) patients showed excellent response to therapy. Three subjects evolved into a different form of idiopathic generalized epilepsy (IGE). No SLC2A1 mutation was identified in 20 (60.6\%) patients tested.

The main clinical features of patients with early-onset absences did not differ from those of CAE except for increased prevalence of males $(p=0.002)$ and longer treatment duration $(p=0.001)$ in the former.

Conclusions: Strong similarities in the electroclinical features and outcome between children with early-onset absences and those with CAE support the view that these conditions are part of the wide spectrum of IGE.

(c) 2011 Elsevier B.V. All rights reserved.

\section{Introduction}

Childhood absence epilepsy (CAE) is a well-defined syndrome characterized by onset of recurrent absences in otherwise healthy, school-aged children (Commission, 1989; Panayiotopoulos, 1997). Patients typically show daily absences ('picnolepsy') consisting of variable consciousness impairment that may be isolated (simple absences) or associated with motor component, automatisms, and autonomic manifestations (complex absences), with concomitant bilateral, regular and symmetrical $3-4 \mathrm{c} / \mathrm{s}$ spike-waves at the EEG (Commission, 1981, 1989; Panayiotopoulos, 1997). Seizures are commonly controlled by antiepileptic drug (AED) treatment and the long-term prognosis is good (Loiseau et al., 2002; Panayiotopoulos, 2005). Only rare cases of absence epilepsy presenting within the first 3 years of life have been reported thus far (Doose, 1994; Chaix et al., 2003; Cavazzuti et al., 1989; Fernandez-Torre et al., 2005; Shahar et al., 2007; Verrotti et al., 2011; Caraballo et al., 2011). Some authors suggest that early-onset absence epilepsy (EOAE) is a distinct syndrome within the spectrum of idiopathic generalized epilepsies (IGE) showing electroclinical features, response to therapy, and prognosis, similar but not identical to CAE (Fernandez-Torre et al., 2005; Shahar et al., 2007). Conversely, other experts consider the early appearance of absences as the first manifestation of various generalized epilepsies with less favourable outcome because of the frequent concomitance of drug-resistance or neurodevelopmental problems (Chaix et al., 2003; Hirsch and Valenti, 2010). Recently, mutations in SLC2A1, encoding the glucose transporter type 1 (GLUT1), have been reported in up to $12 \%$ of subjects with early-onset absence epilepsy (Suls et al., 2009; Mullen et al., 2010).

We evaluated the electroclinical features and the outcome of a large series of patients with absence epilepsy starting before 3 years of life and compared them with those of subjects with a diagnosis of CAE.

\section{Patients and methods}

We reviewed the clinical data (including age, gender, family and personal history of seizures, treatment, and outcome) of patients with typical daily absences observed at different Italian epilepsy centers over a 15-year period. Inclusion criteria were: (1) onset within the first 3 years of life of (2) daily absences accompanied by bilateral, symmetric, and synchronous regular $3-4 \mathrm{c} / \mathrm{s}$ spike-waves with normal background recorded at EEG or video-EEG; (3) other types of seizures and normal development at the onset; and (4) no evidence of brain imaging abnormalities. All the subjects were regularly followed-up at least yearly at each center. Cognition was evaluated by Wechsler Intelligence Scale in patients older than 6 years and by Griffiths scale in younger patients. We also compared the clinical features of the patients with those of children with CAE (age of onset: $3-8$ years) (Commission ILAE, 1981) observed in the same period. An informed consent was signed by all participants or their parents and approval for the study was provided by the Ethics Committee at each center. Statistical analysis was obtained using Student unpaired $t$-test or Fisher's exact test. A $p$-value $<0.05$ was considered to be significant. Mutation analysis of SLC2A1 was performed on genomic DNA by direct sequencing in available patients.

\section{Results}

\section{Clinical data}

We identified 33 patients affected by daily typical absences starting within the 3 years of life and bilateral, symmetric, and synchronous $3-4 \mathrm{c} / \mathrm{s}$ spike-waves at EEG (Figs. 1 and 2). The demographic and clinical data of the patients are shown in Table 1 . There were 20 boys and 13 girls $(M / F$ ratio: $1.54 / 1$ ), with a mean age of $11.9 \pm 8.4$ years (range: 1.6-40.6) at last follow-up. The mean follow-up duration was $9.3 \pm 8.4$ years (range: $1-38$ ). The mean age at seizure onset was $28 \pm 8.0$ months (range: $8-36$ ). In four children, absences appeared within the first year of life (range: 8-11 months). In eight cases (24.2\%) there was at least one first-degree relative (father/mother in three, brother/sister in five) affected by epilepsy, all with IGE. None of the patients showed abnormal neurological examination or associated neurological features, such as paroxysmal dyskinesia. Two children who displayed borderline intellectual functioning $(\mathrm{IQ}=84)$ at long-term (9.33 and 18.16 years) follow-up (Table 1). One subject (patient 26) experienced few generalized tonic-clonic seizures (GTCS) during the period of active absence epilepsy. Other three subjects developed another form of IGE in the following years (IGE with GTCS only in case 27; juvenile myoclonic epilepsy in cases 29 , $30)$. Twenty-eight (85\%) patients became seizure-free with the first antiepileptic drug (AED) (27 valproate, 1 lamotrigine). In the remaining five individuals, the add-on of another AED (4 ethosuximide, 1 levetiracetam) was needed to obtain complete seizure control. During the follow-up period, 12 patients $(60.6 \%)$ were off medication after a mean treatment duration of $6.6 \pm 5.0$ years (range: $1.2-19.6$ ). 
Table 1 Clinical data of the patients with earl-onset absences.

\begin{tabular}{|c|c|c|c|c|c|c|c|c|c|c|c|}
\hline Pt ID & Sex & $\begin{array}{l}\text { Age at last } \\
\text { FW (years) }\end{array}$ & $\begin{array}{l}\text { Familial } \\
\text { history of } \\
\text { epilepsy }\end{array}$ & $\begin{array}{l}\text { Seizure } \\
\text { onset } \\
\text { (months) }\end{array}$ & First AED & $\begin{array}{l}\text { Response to } \\
\text { therapy } \\
\text { (add-on drug) }\end{array}$ & $\begin{array}{l}\text { Follow-up } \\
\text { duration } \\
\text { (years) }\end{array}$ & $\begin{array}{l}\text { Therapy } \\
\text { duration } \\
\text { (years) }\end{array}$ & Cognition & $\begin{array}{l}\text { Subsequent IGE } \\
\text { (onset, years) }\end{array}$ & SLC2A1 analysis \\
\hline 1 & $\sigma^{7}$ & 15 & - & 30 & VPA & Yes & 12.5 & 12.33 & $\mathrm{~N}$ & - & Negative \\
\hline 2 & $\sigma^{7}$ & 4.08 & - & 30 & VPA & Yes & 1.58 & 1.25 & $\mathrm{~N}$ & - & ND \\
\hline 3 & $q$ & 11.08 & - & 32 & VPA & Yes & 8.41 & 7.91 & $\mathrm{~N}$ & - & ND \\
\hline 4 & $0^{x}$ & 10.33 & - & 11 & VPA & ETS & 9.33 & Ongoing & Borderline & - & ND \\
\hline 5 & q & 8.75 & - & 36 & VPA & Yes & 5.75 & 5.58 & $\mathrm{~N}$ & - & Negative \\
\hline 6 & $0^{2}$ & 9.58 & - & 34 & VPA & Yes & 6.75 & 3.8 & $\mathrm{~N}$ & - & ND \\
\hline 7 & $0^{7}$ & 9.41 & - & 36 & VPA & Yes & 6.41 & 3.2 & $\mathrm{~N}$ & - & ND \\
\hline 8 & q & 8.16 & - & 36 & LTG & Yes & 5.16 & Ongoing & $\mathrm{N}$ & - & Negative \\
\hline 9 & q & 1.66 & - & 8 & VPA & LEV & 1 & Ongoing & $\mathrm{N}$ & - & Negative \\
\hline 10 & $0^{2}$ & 12.33 & - & 28 & VPA & Yes & 10 & 3 & $\mathrm{~N}$ & - & Negative \\
\hline 11 & q & 16.5 & Mother (IGE) & 32 & VPA & Yes & 13.91 & 4 & $\mathrm{~N}$ & - & Negative \\
\hline 12 & q & 16.5 & - & 9 & VPA & Yes & 15.75 & 7 & $\mathrm{~N}$ & - & Negative \\
\hline 13 & q & 10.58 & - & 36 & VPA & Yes & 1 & Ongoing & $\mathrm{N}$ & - & Negative \\
\hline 14 & $0^{3}$ & 6 & - & 36 & VPA & ETS & 3 & Ongoing & $\mathrm{N}$ & - & Negative \\
\hline 15 & $0^{7}$ & 14.75 & No & 33 & VPA & Yes & 12 & Ongoing & $\mathrm{N}$ & - & Negative \\
\hline 16 & $0^{x}$ & 7.08 & No & 24 & VPA & Yes & 5.08 & Ongoing & $\mathrm{N}$ & - & Negative \\
\hline 17 & q & 16.83 & $\begin{array}{l}\text { Brother } \\
\text { (IGE) }\end{array}$ & 24 & VPA & Yes & 14.83 & Ongoing & $N$ & - & Negative \\
\hline 18 & $\sigma^{7}$ & 5.01 & Sister (IGE) & 36 & VPA & Yes & 2.08 & Ongoing & $\mathrm{N}$ & - & Negative \\
\hline 19 & $0^{x}$ & 4.83 & No & 33 & VPA & Yes & 2.08 & Ongoing & $\mathrm{N}$ & - & Negative \\
\hline 20 & $0^{7}$ & 3.91 & No & 27 & VPA & Yes & 1.66 & Ongoing & $\mathrm{N}$ & - & ND \\
\hline 21 & q & 21 & $\begin{array}{l}\text { Brother } \\
\text { (IGE) }\end{array}$ & 34 & VPA & Yes & 18.16 & Ongoing & Borderline & - & ND \\
\hline 22 & $0^{7}$ & 5.41 & - & 24 & VPA & Yes & 3.41 & Ongoing & $\mathrm{N}$ & - & ND \\
\hline 23 & $0^{7}$ & 4.16 & - & 29 & VPA & Yes & 1.75 & Ongoing & $\mathrm{N}$ & - & ND \\
\hline 24 & q & 5 & - & 24 & VPA & Yes & 3 & Ongoing & $\mathrm{N}$ & - & ND \\
\hline 25 & $0^{7}$ & 11.41 & - & 24 & VPA & Yes & 9.41 & Ongoing & $\mathrm{N}$ & - & Negative \\
\hline 26 & $0^{x}$ & 32.08 & - & 36 & VPA & Yes & 29.08 & Ongoing & $\mathrm{N}$ & - & Negative \\
\hline 27 & $\sigma^{7}$ & 40.66 & $\begin{array}{l}\text { Brother } \\
\text { (IGE) }\end{array}$ & 24 & VPA & ETS & 38.66 & 19.66 & $N$ & IGEwGTCS (16) & ND \\
\hline 28 & $0^{7}$ & 4.91 & - & 24 & VPA & Yes & 2.91 & Ongoing & $\mathrm{N}$ & - & ND \\
\hline 29 & q & 19.16 & Sister (IGE) & 32 & VPA & Yes & 16.5 & Ongoing & $\mathrm{N}$ & JME (16) & Negative \\
\hline 30 & $0^{7}$ & 19.33 & $\begin{array}{l}\text { Father, } \\
\text { mother } \\
\text { (IGE) }\end{array}$ & 36 & VPA & Yes & 16.33 & Ongoing & $N$ & JME (15) & Negative \\
\hline 31 & q & 7.41 & - & 31 & VPA & Yes & 4.83 & 3.83 & $\mathrm{~N}$ & - & ND \\
\hline 32 & q & 8.41 & Mother (IGE) & 9 & VPA & Yes & 7.66 & Ongoing & $\mathrm{N}$ & - & Negative \\
\hline 33 & $0^{2}$ & 21.66 & - & 30 & VPA & ETS & 19.16 & 8.16 & $\mathrm{~N}$ & - & Negative \\
\hline
\end{tabular}

FW: follow-up; IGE: idiopathic generalized epilepsy; IGEwGTCS: idiopathic generalized epilepsy with generalized tonic-clonic seizures only; JME: juvenile myoclonic epilepsy; AED: antiepileptic drug; VPA: valproate; LTG: lamotrigine; ETS: ethosuximide; LEV: levetiracetam; N: normal; ND: not done. 


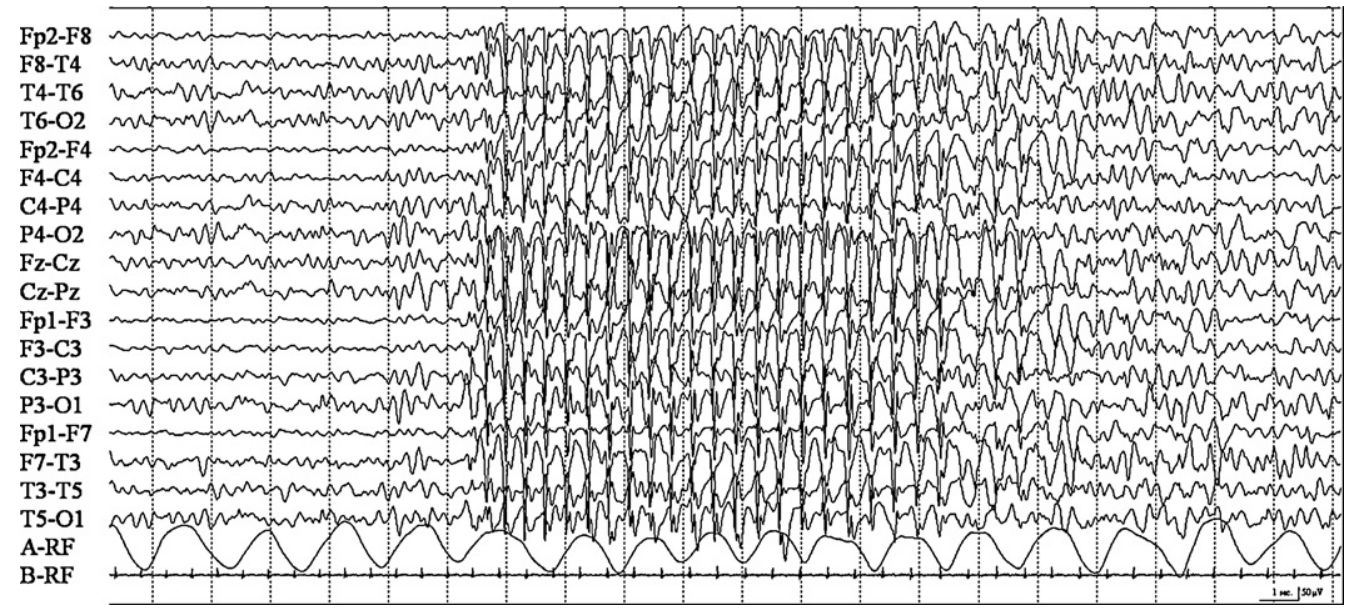

Figure 1 EEG recording of patient \#12 at the age of 2 years showing of symmetric and synchronous generalized spike-and-wave discharges at $3 \mathrm{~Hz}$, lasting 9-10 s and accompanied by interruption of word counting. Low filter: $0.53 \mathrm{~Hz}$; high filter: $35 \mathrm{~Hz}$; notch filter: $50 \mathrm{~Hz}$.

\section{Genetic study}

SLC2A gene analysis was available in $20(60.6 \%)$ patients (Table 1) but no mutations were identified.

\section{Clinical data of CAE patients and statistical analysis}

A total of 912 children with a diagnosis of CAE were observed over a 15-year period. The mean follow-up duration was $7.8 \pm 6.6$ years (range: $1-22$ ). This group included 304 males and 608 females (M/F ratio: 1:2), with a mean age of $7.6 \pm 1.8$ years. First-degree family history of IGE was present in 152 (16.6\%) subjects. GTCS occurred in $103(11.3 \%)$ patients during the period of active absence epilepsy. Thirty-six (3.9\%) children showed borderline intellectual function. The first AED allowed seizure control in the large majority of the patients. Add-on treatment was required in $121(13.2 \%)$ children. Mean treatment duration was $3.8 \pm 1.2$ years (range: $0.6-6$ ).
Statistical analysis showed no difference between IGE family history ( $p=0.24$; Fisher's exact test), occurrence of GTCS $(p=0$. 24; Student $t$-test), intellectual function $(p=0.38$; Fisher's exact test), and number of AEDs $(p=0.79)$ between the two groups except for an increased prevalence of males ( $p=0.002$; Fisher's exact test) and a longer treatment duration $(p=0.001$; Student $t$-test $)$ in patients with early-onset absences.

\section{Discussion}

The occurrence of absence epilepsy before age 3 years is quite infrequent, probably due to the incomplete maturation of specific thalamocortical pathways necessary for generating $3-4 \mathrm{c} / \mathrm{s}$ spike-and-wave complexes (Panayiotopoulos, 1997; Loiseau et al., 2002). So far, less than 50 patients with typical absences starting within the 3 years of life have been reported (reviewed in Shahar et al., 2007). In the last two decades, many authors (Chaix et al., 2003; Fernandez-Torre et al., 2005; Shahar et al.,

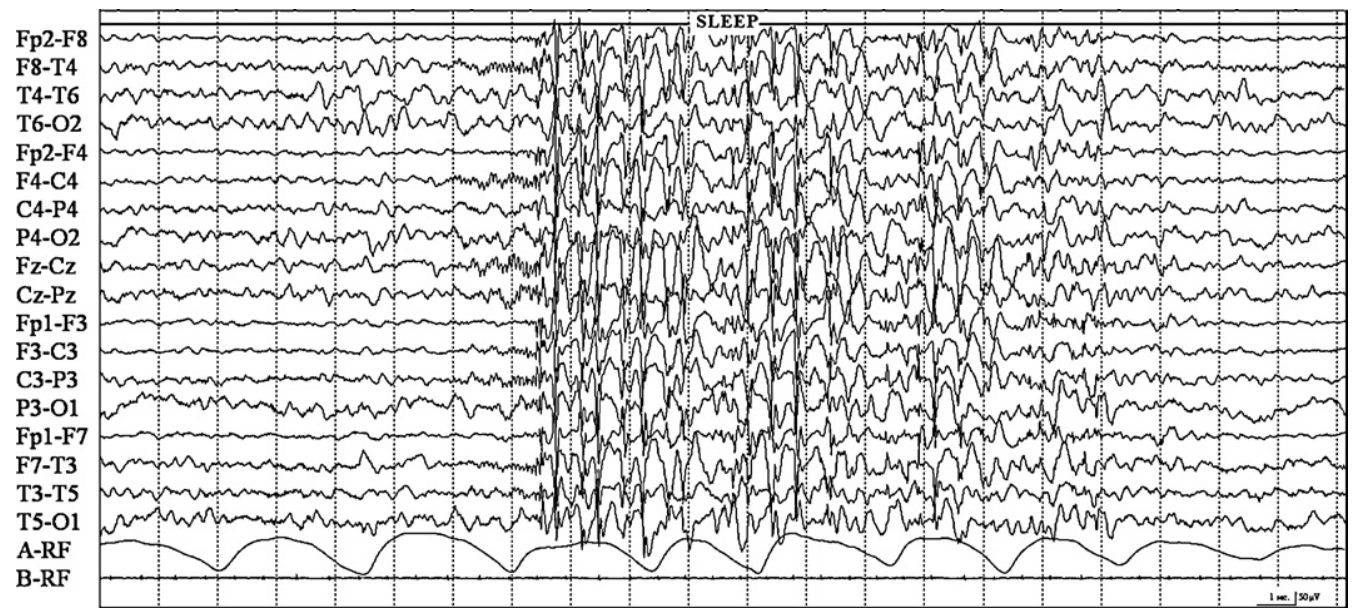

Figure 2 Sleep EEG recording of patient \#15 obtained at the age of 30 months and showing rhythmic 3- $\mathrm{Hz}$ spike-and-wave complexes preceded by sleep spindles over the anterior regions. Low filter: $0.53 \mathrm{~Hz}$; high filter: $35 \mathrm{~Hz}$; notch filter: $50 \mathrm{~Hz}$. 
2007; Verrotti et al., 2011) have attempted to delineate the electroclinical and the outcome of these patients. However, whether this should be considered a distinct epileptic syndrome within the spectrum of IGE is still unclear. Indeed, in a recent study, Caraballo et al. (2011) showed that absences starting in the first years of life may occur in children with different epileptic syndromes, such as CAE, benign myoclonic epilepsy of infancy, and eyelid myoclonia with absences. Moreover, while strongly advocated by some authors (Cavazzuti et al., 1989), the view that these children show less favourable seizure control and impaired cognitive is refused by other experts (Fernandez-Torre et al., 2005; Shahar et al., 2007). These differences could be due to different inclusion criteria and study design within these series. Alternatively, it can be more easily explained by the evolving concept of epilepsy syndrome, its dynamic characteristics and the extremely complex pathophysiologic mechanisms underlying the epileptic phenomena (Striano et al., 2009).

Here, we report the results of a multicenter study including different epilepsy center from Italy.

This is the largest series of patients with typical absences starting within the 3 years of life reported thus far. Our sample represents about the $3.5 \%$ of all subjects with absence seizures ('picnolepsy') observed in the same period. The main finding of our study is the evidence that clinical and EEG features of patients with absences starting before age 3 years do not significantly differ from those of children with typical CAE. Previous studies suggested that GTCS predict poor prognosis in CAE (Grosso et al., 2005). In our study, we found no correlation between the clinical outcome of the patients and the presence of GTCS, according to other authors (Wakamoto et al., 2010). Likewise, response to the therapy and the global outcome of the two groups of patients are quite similar. Therefore, we cannot confirm the view that children with early-onset absences have a less favourable prognosis and more neurodevelopmental problems respect to those with a diagnosis of CAE. The reason for this discrepancy is uncertain but it could depend from enrollment bias and different inclusion criteria in other studies, such as the exclusion of other seizure types and cognitive impairment at the onset.

The male prevalence in the group of patients with earlyonset absences could result from a bias due to the still unexplained higher incidence of CAE in girls (Loiseau et al., 2002; Panayiotopoulos, 2005). In addition, we observed a longer treatment duration in the group of patients with early-onset absences respect to those with CAE. This is probably due to the earlier age at seizure onset and to the tendency for referring clinicians to continue the therapy until late childhood in this group.

Some patients from our series developed different forms of IGE in later age, confirming the existence of a continuum between IGE from early to adulthood (Panayiotopoulos, 1997). In addition, the finding that almost a quarter of our patients had a first-degree relative affected by IGE would confirm that the important role of genetic factors in the etiology of absence epilepsy (Doose, 1994; Loiseau et al., 2002; Panayiotopoulos, 2005).

Mutations in SLC2A1 are a well-know cause of glucose transporter-1 (GLUT1) deficiency (OMIM 606777), a severe disorder that results in acquired microcephaly, intractable epilepsy, developmental delay, and additional neurologi- cal manifestations (e.g., ataxia or movement disorders) (Klepper, 2011). However, in the last few years several observations have significantly expanded this phenotype to include variable age at onset and a wide spectrum of clinical manifestations, including refractory and early-onset absence seizures (Roulet-Perez et al., 2008; Suls et al., 2009; Slaughter et al., 2009; Mullen et al., 2010; Byrne et al., 2011; Klepper, 2011) and the same authors have demonstrated a permanent frontal hypometabolism in such patients (Suls et al., 2008). We failed to identify SLC2A1 mutations in the 20 screened patients, probably due to the fact that we did not identify children with additional neurological findings other than epilepsy. Further studies should assess the diagnostic impact of SLC2A1 screening in patients with absence epilepsy and other IGE. However, we could speculate that in most cases these epilepsies follow complex inheritance with multiple genes probably contributing to its aetiology as in most common forms of IGE (Gardiner, 2005).

In summary, we showed that-although rarely-typical absences epilepsy can occur before 3 years of age. The earlier onset of absences does not necessarily imply a poor prognosis. Indeed, the strong similarities in the main electroclinical features and outcome between children with early-onset absences and those with CAE support the view that these conditions are a continuum within the wide spectrum of IGE. These findings also confirm the difficulty to identify evidence-based instruments to devise a syndromic classification of epilepsies useful for clinical practice.

\section{References}

Byrne, S., Kearns, J., Carolan, R., Mc Menamin, J., Klepper, J., Webb, D., 2011. Refractory absence epilepsy associated with GLUT-1 deficiency syndrome. Epilepsia (March) [Epub ahead of print].

Caraballo, R.H., Darra, F., Fontana, E., Garcia, R., Monese, E., Dalla Bernardina, B., 2011. Absence seizures in the first 3 years of life: an electroclinical study of 46 cases. Epilepsia 52, 393-400.

Cavazzuti, G.B., Ferrari, P., Galli, V., Benatti, A., 1989. Epilepsy with typical absence seizure with onset during the first years of life. Epilepsia 30, 802-806.

Chaix, I., Daquin, G., Montiero, F., Villeneuve, N., Laguitton, V., Genton, P., 2003. Absence epilepsy with onset before age three years: a heterogeneous and often severe condition. Epilepsia 44, 944-949.

Commission on Classification and Terminology of the International League Against Epilepsy, 1981. Proposal for revised clinical and electroencephalographic classification of epileptic seizures. Epilepsia 22, 489-501.

Commission on Classification and Terminology of the International League Against Epilepsy, 1989. Proposal for revised classification of epilepsies and epileptic syndromes. Epilepsia 30, 389-399.

Doose, H., 1994. Absence epilepsy of early childhood. Genetic aspects. Eur. J. Pediatr. 153, 372-377.

Fernandez-Torre, J.L., Herranz, J.L., Martinez-Martinez, M., Maestro, I., Barrasa, J., 2005. Early onset absence epilepsy: clinical features in three children. Brain Dev. 28, 311-314.

Gardiner, M., 2005. Genetics of idiopathic generalized epilepsies. Epilepsia 46 (Suppl 9), 15-20.

Grosso, S., Galimberti, D., Vezzosi, P., et al., 2005. Childhood absence epilepsy: evolution and prognostic factors. Epilepsia 46, 1796-1801. 
Hirsch, E., Valenti, M.P., 2010. Other probable syndromes of idiopathic generalized epilepsies. In: Panayiotopoulos, C.P. (Ed.), Atlas of Epilepsies. London Limited, Springer-Verlag, pp. 1055-1060 (Chapter 155).

Klepper, J., 2011. GLUT1 deficiency syndrome in clinical practice. Epilepsy Res. (March) [Epub ahead of print].

Loiseau, P., Panayiotopoulos, C.P., Hirsch, E., 2002. Childhood absence epilepsy and related syndromes. In: Roger, J., Bureau, M., Dravet, C., Genton, P., Tassinari, C.A., Wolf, P. (Eds.), Epileptic Syndromes in Infancy, Childhood and Adolescence., 3rd edition. John Libbey \& Co. Ltd., London, pp. 285-303.

Mullen, S.A., Suls, A., De Jonghe, P., Berkovic, S.F., Scheffer, I.E., 2010. Absence epilepsies with widely variable onset are a key feature of familial GLUT1 deficiency. Neurology 75, 432-440.

Panayiotopoulos, C.P., 1997. Absence epilepsies. In: Engel Jr., J., Pedley, T.A. (Eds.), Epilepsy: A Comprehensive Textbook. Lippincott-Raven, Philadelphia, pp. 2327-2346.

Panayiotopoulos, C.P., 2005. Idiopathic generalized epilepsies recognized by the international league against epilepsy. Epilepsia 46, 48-56.

Roulet-Perez, E., Ballhausen, D., Bonafé, L., Cronel-Ohayon, S., Maeder-Ingvar, M., 2008. Glut-1 deficiency syndrome masquerading as idiopathic generalized epilepsy. Epilepsia 49, 1955-1958.

Shahar, E., Genizi, J., Nevo, Y., Kaufman, R., Cabot, S., Zelnik, N., 2007. Typical absence epilepsy presenting prior to age of 3 years: an uncommon form of idiopathic generalized epilepsy. Eur. J. Paediatr. Neurol. 11, 346-352.
Slaughter, L., Vartzelis, G., Arthur, T., 2009. New GLUT-1 mutation in a child with treatment-resistant epilepsy. Epilepsy Res. 84, 254-256.

Striano, P., Striano, S., Beghi, E., Capovilla, G., 2009. Comment on "Factors influencing clinical features of absence seizures". Epilepsia 50, 2003-2004.

Suls, A., Dedeken, P., Goffin, K., Van Esch, H., Dupont, P., Cassiman, D., Kempfle, J., Wuttke, T.V., Weber, Y., Lerche, H., Afawi, Z., Vandenberghe, W., Korczyn, A.D., Berkovic, S.F., Ekstein, D., Kivity, S., Ryvlin, P., Claes, L.R., Deprez, L., Maljevic, S., Vargas, A., Van Dyck, T., Goossens, D., Del-Favero, J., Van Laere, K., De Jonghe, P., Van Paesschen, W., 2008. Paroxysmal exerciseinduced dyskinesia and epilepsy is due to mutations in SLC2A1, encoding the glucose transporter GLUT1. Brain 131, 1831-1844.

Suls, A., Mullen, S.A., Weber, Y.G., Verhaert, K., Ceulemans, B., Guerrini, R., Wuttke, T.V., Salvo-Vargas, A., Deprez, L., Claes, L.R., Jordanova, A., Berkovic, S.F., Lerche, H., De Jonghe, P., Scheffer, I.E., 2009. Early-onset absence epilepsy caused by mutations in the glucose transporter GLUT1. Ann. Neurol. 66, 415-419.

Verrotti, A., Olivieri, C., Agostinelli, S., Coppola, G., Parisi, P., Grosso, S., Spalice, A., Zamponi, N., Franzoni, E., lannetti, P., Chiarelli, F., Curatolo, P., 2011. Long term outcome in children affected by absence epilepsy with onset before the age of three years. Epilepsy Behav. 20, 366-369.

Wakamoto, H., Fukuda, M., Shigemi, R., et al., 2011. Atypical childhood absence epilepsy with preceding or simultaneous generalized tonic clonic seizures. Pediatr. Neurol. 44, 183-186. 